\title{
ENTRE UM RECEPCIONISTA DE HOTEL E UM TRAVESTI NUMA CIDADE TURÍSTICA: O NÃO LUGAR
}

José Carlos Mariano do Carmo ${ }^{47}$

RESUMO: O objetivo do trabalho é verificar o enredo da obra inovadora de Carlos Henrique Schroeder "As fantasias eletivas", na cidade turística de Balneário Camboriú, Santa Catarina. Do ponto de vista espacial, a possibilidade de amizade entre um recepcionista de hotel e uma travesti. A questão de identidade e as possíveis relações que podem ser estabelecidas com o clássico "As afinidades eletivas", de Goethe. Além disso, a partir da teoria do não lugar, de Marc Augé, as tantas possibilidades que também lugares de indiferença e de trânsito podem apresentar como sendo passiveis de acontecimentos inusitados, entre a fotografia, a poesia e a literatura. Os protagonistas quebram o paradigma da transitoriedade, numa permanência de amizade que permeia caminhos possiveis no entre-lugar entre a Argentina e o Brasil. Ao mesmo tempo, as possibilidades de transformações entre as personagens, seja do ponto de vista cultural, seja do ponto de vista humano. A cidade turística não apenas como espaço de turismo ou de violência, mas como imersa numa solidão profunda de objetos e de relacionamentos humanos. $\mathrm{O}$ afeto e as trocas simbólicas culturais num espaço permeado pela paisagem como reduto/redutor do turismo, ora transformado em literatura.

Palavras-chave: Schroeder. Fotografia. Marc Augé. Não lugar e entrelugar. Literatura.

ABSTRACT: The objective is to check the plot of the innovative work of Carlos Henrique Schroeder "Elective fantasies", in the resort town of Balneario Camboriu, Santa Catarina. The spatial point of view, the possibility of friendship between a hotel receptionist and a transvestite. The question of identity and the possible relationships that can be established with the classic "Elective Affinities" by Goethe. An also, based

${ }^{47}$ Doutor em Teoria Literária pela Universidade Federal de Santa Catarina-UFSC. Professor da Faculdade SENAC em Florianópolis e da Faculdade Educacional da Lapa- FAEL. 
on Marc Augé 's theory of no-place, the many possibilities that places of indifference and transit areas may have to be subject for unusual events, between photography, poetry and literature. The protagonists break the paradigm of transience, in a friendship of permanence that permeates possible paths in the in-between place between Argentina and Brazil. And at the same time, the possibilities for transformations between the characters, be it from a cultural standpoint or from a human point of view. The resort town not only as tourist space or violence, but as immersed in deep loneliness of objects and human relationships. The affection and cultural symbolic exchanges in a space pervaded by the landscape as redoubt/reducer of tourism, now transformed into literature.

Keywords: Schroeder. Photography. Marc Augé. No place and inbetween. Literature.

A obra de Carlos Henrique Schroeder mostra-se inovadora ao apresentar personagens que fogem do senso comum. Com um narrador em terceira pessoa, o livro publicado em 2014 é uma clara homenagem ao escritor argentino Raúl Natalio Roque Damonte Botana que tem como apelido Copi, provavelmente oriundo da expressão "un copito de nieve" ou, ainda, o nome tenha surgido a partir do anagrama "pico". A obra, As fantasias eletivas, apresenta dois personagens intrigantes: o Renê, recepcionista de hotel, e a travesti argentina Copi, ambos em Balneário Camboriú.

O romance é dividido em quatro partes:

$\mathrm{S}$ de sangue;

A solidão das coisas;

Poesia completa de Copi;

As fantasias eletivas.

O titulo, possivelmente, tenha sido oriundo de outro romance: As afinidades eletivas, de Goethe, o mais antigo romance alemão, publicado em 1809 onde o autor "se destinava a demonstrar a origem química do amor", conforme prefácio da obra por R. J. Hollingdale. Os opostos se atraem, mas, muitas vezes, não se misturam. É o que Goethe afirma:

Da maneira contrária, outros permanecerão estranhos entre si e não se ligarão, ainda que sejam mecanicamente friccionados e misturados, à maneira do óleo e da água, 
que, juntados num recipiente que se agita, em seguida retornam ao estado de separação. (GOETHE, 2014, p. 55).

O escritor Schroeder constrói a narrativa apresentando em cada capítulo a letra do abecedário correspondente, mas não segue essa ordem linear: ela vai além. A questão da impossibilidade da mistura da água e do óleo aparece logo no início:

Chegou rubro ao banheiro, lavou o rosto, olhou-se no espelho. Precisava se controlar, não podia colocar tudo a perder de novo, ela não merecia. Mas era como uma chave de fenda, que ia fundo, dilacerando o peito. E chorou mais uma vez, por ser fraco, por não controlar esse monstro, por não estar curado. Seria a palavra correta, curado? Como se cura algo que é de sua natureza? Como se separam óleo e água depois de misturados? (SCHROEDER, 2014, p.13).

O narrador não tem certeza acerca da química do amor de Goethe, embora possa ser explicado de maneira química e/ou fisicamente, as relações afetivas e os desejos também não apresentam necessariamente essa lógica. Renê tenta o suicídio logo no início do romance, alternando a narrativa entre terceira pessoa, a do narrador, e a primeira pessoa, a do personagem:

Eu não quero falar agora, pois sei que falarei a verdade: nasci, cresci, casei, tive um filho, quase matei meu filho e minha esposa, me divorciei, fiquei dois anos bebendo como um louco, tentei me afogar, mas nada disso me pareceu grandioso, heroico, sedutor. (SCHROEDER, 2014, p. 15).

A declaração ganha uma lente de aproximação. Não se sabe o motivo pela tentativa de assassinato da esposa e do filho, há indícios na obra de que tenha sido por ciúme.

Nos capítulos "B" e "C" o narrador, em terceira pessoa, retoma seu posto e mostra como Renê é esfaqueado no trajeto entre o hotel que trabalha e sua casa, agora vítima do ciúme de um adolescente. O protagonista está com 34 anos. $\mathrm{O}$ trajeto elenca nome de ruas que são um mapa dos que vivem à margem: Paraguai, Paquistão, Palestina e, ainda, a 
roupa de poliéster do hotel, composto por camisa bege e calça vermelha. A facada não parece ter sido apenas por ciúme, mas por um tênis Commander e pelos "olhos de futuro de Renê", nas palavras do narrador.

No capítulo "D", a questão do destino como "filosofia eletiva", mas não a romântica de Goethe, conforme Renê responde à namorada Maria, que quer saber se ele acredita em destino: "Sinceramente, não sei, muitas vezes sim, mas aí também imagino que, se há destino, deve haver alguém comandando, e aí tudo me parece sem sentido, uma piada de mau gosto." (SCHROEDER, 2014, p. 21). Qual seria o sentido de um destino previamente roteirizado?

Renê representa a mão de obra explorada: "Este era seu primeiro dia de folga depois de quatro meses sem um dia livre sequer, e, embora gostasse muito de Maria, a tainha realmente havia acabado com ele, mais uma vez" (p. 22). Chamado de Mister Álcool, pois costumava passar álcool constantemente na mesa de mármore de recepção, Renê é então convidado pelo Senhor Afonso, dono do Hotel, a trabalhar no período noturno e a substituir dois funcionários que seriam demitidos. É a ironia do destino? Ou aceita ou seria também demitido e sem possibilidade de trabalho:

E numa cidade essencialmente turística como Balneário Camboriú, sem indústrias, só havia quatro caminhos: ser vendedor de alguma loja, garçom, trabalhar num hotel ou arrumar uma teta na prefeitura. (SCHROEDER, p. 24).

Neste aspecto, a força econômica da exploração desafia o personagem, sem opção. Renê escolhe o período noturno.

No capitulo "F", desenvolve-se o enredo do personagem Renê que é rejeitado pelos pais que não o perdoam pelo que fez à mulher e ao filho Leo. Mas Renê parece transformado e pede perdão, sem sucesso. A saudade do filho é terrivel:

A primeira coisa que Renê comprou quando retornou para Balneário Camboriú foi um sabonete da Turma da Mônica, para sentir o cheiro do filho, para ter o cheiro do filho na hora que quisesse (SCHROEDER, 2014, p. 27).

A questão da percepção é forte no romance, por isso cheirar o sabonete para matar a saudade do filho e por isso, também, a solidão do 
olhar, num quarto de hospital: "Havia um imenso louva-deus verde no seu quarto, exatamente sobre sua cama, no teto." (SCHROEDER, 2014, p. 32)

Ao mesmo tempo em que o romance vem acompanhado por essas memórias, descreve-se a vida atual do personagem Renê como recepcionista de hotel, no que poderíamos denominar de não lugar, dentro da concepção teórica do antropólogo francês Marc Augé:

Os não lugares são tanto as instalações necessárias à circulação acelerada de pessoas e bens (vias expressas, trevos rodoviários, aeroportos) quanto os próprios meios de transporte ou os grandes centros comerciais, ou ainda, os campos de trânsito prolongado onde são alojados os refugiados do planeta. (AUGÉ, 1994, p. 36, grifos meus).

Do ponto de vista antropológico, o não lugar é onde se apagam as identidades. Não por acaso, esse é um tema interessantíssimo, justamente quando muitos refugiados emigram à procura de lugares. Augé cita claramente os "campos de trânsito" como sendo não lugares. Não se trata aqui, meramente, da diferença entre "autóctones" e "alóctones", dividindo territórios. Existem espaços que são marcados de uma impessoalidade que tornam muitos seres humanos invisiveis. Talvez seja importante definir os lugares para entender os não lugares, conforme Augé:

Esses lugares têm pelo menos três características comuns. Eles se pretendem (pretendem-nos) identitários, relacionais e históricos. O projeto de casa, as regras de residência, os guardiões da aldeia, os altares, as praças públicas, o recorte das terras correspondem para cada um a um conjunto de possibilidades, prescrições e proibições cujo conteúdo é, ao mesmo tempo, espacial e social. Nascer é nascer num lugar, ser designado à residência. Nesse sentido, o lugar de nascimento é constitutivo de identidade individual (...). (AUGÉ, 1994, p. 52, grifos meus).

As três características de lugares quase não aparecem numa recepção de um hotel: é difícil manter qualquer relacionamento mais aprofundado, a não ser para solicitar a chave do quarto ou alguma 
informação turística. Sabemos que o hotel do romance de Schroeder além de ser não lugar, quando o é, é para satisfazer os desejos dos hóspedes que procuram: prostitutas, travestis, michês e drogas. Não há nesse não lugar de passagem "memória histórica" e nem "lugares de memória", ainda que se viva qualquer evento relacionado a esses aspectos eles são passageiros do tempo efêmero de um evento ou de relações sexuais em Balneário Camboriú. Não há maiores identidades de relacionamentos afetivos. Sabe-se que a cidade está lá para receber turistas, tem praia, algum passeio e muitas "transações", dispersas em quase nenhum monumento. Nesses lugares, sem generalizações, o sujeito turista não possui nenhuma das três características que poderiam defini-lo como pertencente a um lugar:

- está de passagem;

- não tem interesse em relacionamentos aprofundados, mas sim os mediados pelo dinheiro;

- tem curiosidade histórica visual, muitas vezes guardada por fotografias, mas que não se acrescentam quase nada à sua "memória histórica" de identidade;

- embora reconheça os valores históricos do lugar visitado, tem pouco interesse em "viver essa história".

Portanto, nas condições de Renê e da travesti Copi há um duplo não lugar: Renê é originário, possivelmente, de outra região de Santa Catarina ou do Brasil e Copi é da Argentina, mais especificamente de Las Heras, em Mendoza. Ambos estão em Balneário Camboriú para trabalhar e recomeçar: Renê enquanto recepcionista de hotel no período noturno e Copi enquanto travesti. Nas cidades turisticas há superabundância de tudo e o viajante viaja por prospectos de propaganda: "O espaço do viajante seria, assim, o arquétipo do não lugar.” (AUGÉ, 1994, p. 81) Os nomes próprios das estações do metrô em Santiago do Chile, por exemplo, para os turistas de passagem, nada mais são do que condição passageira e, a história, existe somente naquele momento de trânsito, de um lugar para outro. $\mathrm{O}$ nome e o espaço das estações de metrô, para muitos dos turistas, constitui um não lugar, pois não se insere, a não ser na forma de passagem, em sua "memória histórica". Esse olhar não pode ser generalizado, pois há turistas interessados justamente em registrar esses nomes, estudar os mapas para além da necessidade de se chegar a algum lugar e outras características, mas não se trata dessas exceções e, sim, do grande contingente de turistas que formam esses não lugares: 
Vê-se bem que por "não lugar" designamos duas realidades complementares, porém, distintas: espaços constituídos em relação a certos fins (transporte, trânsito, comércio, lazer) e a relação que os indivíduos mantêm com esses espaços. Se as duas relações se correspondem de maneira bastante ampla e, em todo caso, oficialmente (os indivíduos viajam, compram, repousam), não se confundem, no entanto, pois os não lugares medeiam todo um conjunto de relações consigo e com os outros que só dizem respeito indiretamente a seus fins: assim como os lugares antropológicos criam um social orgânico, os não lugares criam tensão solitária. (AUGÉ, 1994, p. 87, grifos meus).

Os não lugares estabelecem um contrato individual de entrada e outro de saída e o usuário é obrigado a provar sua inocência, sendo vigiado constantemente: "O espaço do não lugar não cria nem identidade singular nem relação, mas sim solidão e similitude.” (AUGÉ, 1994, p. 95) Os dois protagonistas do romance Schroeder vivem essa solidão e essa similitude de viver para o trabalho numa cidade não lugar. É claro que a cidade é um lugar para muitas pessoas que lá residem, tem relacionamentos, criaram raízes históricas. Não por acaso, afirma o narrador:

Numa cidade turística tudo tem preço, informação, prazer, sossego, vingança. E Renê sabe disso, e estava fora dos esquemas mais pesados, pois tinha medo, sobretudo da cadeia. Ariel era o recepcionista que mais fazia dinheiro no hotel, com todos os tipos de negócios. Mas o que vinha se mostrando mais lucrativo era o ramo da fotografia: tinha um amigo que era técnico de informática, e copiava e imprimia fotos de crianças que pegava do HD de seus clientes. Ele vendia para Ariel, que por fim repassava para clientes do país todo e do exterior. A imagem do desejo, o desejo pela imagem. A cidade de Balneário Camboriú, um aglomerado de prédios em menos de cinquenta quilômetros quadrados, recebia mais de um milhão de turistas por ano na alta e média temporada, e era um dos principais destinos turísticos de Santa Catarina, para sua sorte e desgraça. Era também uma cidade de recomeços, 
muitas pessoas vinham para a cidade sepultar o passado, como Renê, como Copi. (SCHROEDER, 2014, p. 36, Grifos meus).

Quanto mais o passado é renegado para um recomeço, mais a memória histórica e a solidão entram enquanto componentes psicológicos de Renê e de Copi. Renê sente forte saudade do filho e Copi, enquanto travesti, é renegada pela família. A cidade respira "comissões". Os recepcionistas de hotel conhecem bem essa realidade:

Você trabalha sábados, domingos, feriados, Natal, AnoNovo e seus pagamentos são mensais. Os taxistas sempre no dia primeiro. Três reais por táxi chamado. As putas dão dez por cento do valor do programa, ou pagam em boquetes e rapidinhas; os travestis, vinte por cento, e a michezada, quinze. Os traficantes pagam na hora, em mercadoria ou dinheiro (SCHROEDER, 2014, p. 39).

Essa hierarquia de valores, a partir dos taxistas chamados pelo hotel, são características do não lugar com superabundância de comissões, com circulação de dinheiro e negócios. Copi teve que lutar para conseguir deixar seu "book" com Renê, então repleto de preconceitos. No anúncio da travesti Copi, lê-se no capítulo "K": "Copi. Travesti magra, bonita, bem-vestida e inteligente. Nivel universitário. Ativa e passiva: não decepciona, prazer além da carne. Atendo local próprio e sem portaria." (SCHROEDER, 2014, p.40). Já Renê é heterossexual convicto e prefere a prostituta Kelly que, além de permitir uma comissão maior, ainda é uma loiraça que "(...) honrava a palavra boquete, com muita suculência." (SCHROEDER, 2014, p. 42).

A relação de Renê com Copi vai se estreitando, numa amizade imprevisivel. Enquanto leitores, temos sempre a ideia de que estaremos na iminência da relação sexual entre os dois, desafiados constantemente pela convicção de heterossexualidade do personagem Renê. $O$ que se vai tecendo no romance é uma amizade entre um recepcionista de hotel, bronco até certo ponto, mas sensível aos apelos de amizade advindos de Copi. A disparidade cultural apenas os aproxima e os contrários se atraem e se misturam: 
A primeira vez que Renê viu uma biblioteca que não fosse num órgão público foi no apartamento de Copi. Ao lado da porta havia uma estante abarrotada de livros, e Renê achava aquilo engraçado, pra que serviriam livros para um traveco, pensava (mas não dizia). Até que soube a trajetória de Copi: do nascimento em Las Heras, na província de Mendoza, até o curso de jornalismo em Buenos Aires, onde caiu na noite portenha. O estágio como assistente de $\mathrm{El}$ Clarin, as tentativas de seguir os caminhos da escrita e seu retorno para Mendoza. E, por fim, a coragem de fazer o que achava que devia fazer (SCHROEDER, 2014, p. 45).

É Copi quem vai desfiar a teia da sociedade moderna, em que a tecnologia, o poder e o ter precedem as relações de afeto e ela afirma:

"Você não vê mais as pessoas namorando na rua, quase não vê o beijo, o afago, aquele abraço prolongado. Apenas o mecânico e desgastado andar de mãos dadas. Os adolescentes ainda se beijam ardorosamente, ficam pendurados um no pescoço do outro ou mesmo partem para um amasso de proporções godzillescas. Mas e os adultos? Os bancos das praças e praias, principalmente dessa merda de praia suja do centro, se transformaram num lugar de descanso e observação, onde se espera acabar o sorvete para continuar a caminhada, ou onde dá para espiar os carros passando, ou onde se mata o tempo. Cadê os beijos nos bancos? Aqueles que nos deixam sem jeito, que dão inveja? A paixão, essa vermelha e ardilosa lei da natureza, que fez com que eu e você estivéssemos aqui hoje, que fez com que nossos pais sentissem algo carnal, químico ou metafísico um pelo outro, está expulsa da vida pública. Nos permitimos exibir nossos carros, a porra desses tijolões, os celulares, mas temos vergonha de fazer um carinho, dar um beijo prolongado na nossa companhia em plena rua. É uma espécie de ausência que torna todas as ruas de todas as cidades um pouco fantasmas, já que elas deixaram de ser o palco das expressões humanas para ser apenas um trajeto. As ruas, que já foram significado de liberdade e revolta, hoje significam medo e violência. Está difícil até para nós, 
que somos crias das ruas. Ausência, esta é a palavra. O afeto não é mais público, ninguém se importa mais com o afeto, das pessoas, das coisas, das árvores. Eu pensei que você está entendendo, Ratón, você é a porra de um caipira lá do interior, mas ...”. (SCHROEDER, 2014, p. 61, grifos meus).

O desencanto de Copi com o mundo moderno e sua tralha tecnológica que, em muitos casos, não diminui as desigualdades e, ainda, acaba com o afeto em público: tudo parece se tornar cada vez mais funcional, a serviço do trabalho e da exploração capitalista. Copi desenvolve toda uma filosofia de desejos e não apenas de afinidades, embora também as considere. A ausência permeia as relações afetivas do ser humano. Há, no discurso de Copi, uma intersecção com a teoria desenvolvida por Marc Augé, exatamente sobre os não lugares nas ausências de: identidade, relacionamentos afetivos (memória afetiva) e memória histórica:

Onde eu estava, ah, as fotografias, a ausência vai permeando tudo. Somos a todo instante impelidos para ela, para fugir do contato humano. Televisões invadiram todos os espaços: rodoviárias, aeroportos, bares, academias e escolas. E nós não olhamos mais para as pessoas, mas sim para as telas. E elas dizem que não devemos mais conversar, e sim olhar para a tela. Não devemos mais olhar para os pássaros, para as árvores, para as pessoas, mas sim para a tela. É uma troca, do real pelo virtual. Onde vai parar essa porra? E essa troca é também ausência. Não preciso nem dizer que alguém está lucrando com isso, a todo momento. Não duvido de que alguns anos os celulares se transformem numa espécie de televisão. E na ausência, nas telas, vão-se os enamoramentos, vai-se a paixão, e fica um vazio enorme dentro do nosso peito. Te falei que eu quebrei minha televisão? Esse lixo! Joguei ela no chão, a vaca... (SCHROEDER, 2014, p. 62, grifos meus).

É a Sociedade do Espetáculo na visão de Guy Debord. Copi também relaciona a literatura com a fotografia, numa espécie de sentido. Não por acaso, a fotografia é um dos principais elementos dos celulares na vida 
moderna: fotos selfies invadem a vida virtual e provocam um vazio na comunicação face a face, além da ausência de afeto da vida moderna. Mas não é dessa fotografia que nos fala Copi: ela a apresenta como a apreensão de um momento poético e na solidão de seres humanos e das coisas. A relação é direta, pois a literatura também desvela imagens: "Meu interesse pela fotografia começou justamente para tentar entender um pouco mais os processos literários; afinal, criar e contar histórias é desvelar imagens." (SCHROEDER, 2014, p. 66).

É por isso que o próximo capitulo é "A solidão das coisas", em que Copi fotografa a solidão. Um relógio, sempre fotografado sem movimento, parado; um bar de hotel em que se exercita muita solidão; um marcador de páginas; uma cruz no topo de um morro inacessível e assim por diante. Até certo ponto, os locais em que tais objetos são flagrados são também espaços de memória, afetiva ou não, em que o tempo para, em forte solidão e invisibilidade social. Renê e Copi, num certo sentido, são invisiveis socialmente e somente são lembrados para que se solicite a chave do quarto de hotel onde se está hospedado, para informações turísticas ou para pagar prostitutas e michês, sendo o recepcionista o mediador entre os hóspedes que procuram por "relações sexuais" ou, ainda, para compra de drogas; Copi, por outro lado, somente é lembrada para a compra de sexo, ativo ou passivo. Os objetos fotografados tornam-se metáforas em relação aos seres humanos esquecidos, párias da sociedade mercantilista moderna. É bem sintomático o caso dos orelhões, para citar um exemplo:

Os telefones públicos, os populares orelhões, amargam a exclusão completa, imposta pela popularização dos celulares. Pesquisas indicam que $78 \%$ dos orelhões consomem entorpecentes. Eles tornaram-se um grave problema social, pois é provável que mais da metade deles caia na indigência. Em todos os cantos do país é possível vêlos, sempre sozinhos, cabisbaixos e tristes, à espera de um milagre. (SCHROEDER, 2014, p. 88)

O penúltimo capítulo é dedicado à "Poesia completa de Copi", destacando-se, por exemplo, o seguinte poema: 


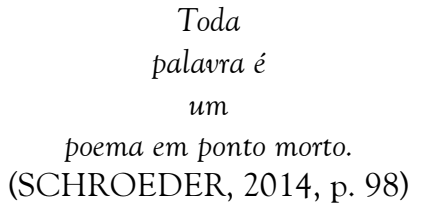

A subversão é algo marcante na obra do escritor Schroeder que, inusitadamente, insere uma relação de afeto numa sociedade mercantilista, mediada por comissões, entre Renê e Copi. Se Renê ficou apenas na tentativa, a Copi deixou para ele todo um arcabouço teórico de relacionamento humano. Mas o mais importante é a possibilidade de se relacionar, enquanto afeto e amizade, com fantasias eletivas, além de afinidades. Não se tratam de fantasias sexuais, mas sim de poesia, fotografia, literatura, palavra, entre tantos exemplos que poderiam ser citados.

Ambos não são apenas personagens de um romance qualquer, mas estando num não lugar, eles estabelecem uma relação que torna a cidade turística de Balneário Camboriú, foco de impessoalidade, como cidade lugar de possibilidades. Este aspecto subverte a ordem turística do sexo casual por dinheiro, do turismo apenas como passagem ou de trajeto num não lugar. A recepção do hotel não é mais apenas para a chave de um quarto qualquer, mas a chave que descortina um universo de possibilidades.

Se o escritor Schroeder tem como ponto de partida a literatura de Raúl Damonte Botana, ou seja, a do escritor Copi, convém afirmar que ambos se inserem na subversão da literatura latino-americana, antropofágica, fora do centro. Ambos, também, inserem um segundo texto ou, ainda, textos sobre outros textos: palimptextos, neologismo para palimpsestos. Não se trata mais de literatura ingênua, mas aquela que nos intranquiliza, que nos questiona e que desafia o cânone literário. As obras de Schroeder e as do escritor Copi desafiam outros textos. Silviano Santiago explica:

Nesse sentido, as críticas que muitas vezes são dirigidas à alienação do escritor latino-americano, por exemplo, são inúteis e mesmo ridículas. Se ele só fala de sua própria experiência de vida, seu texto passa despercebido entre seus contemporâneos. (...) $\mathrm{O}$ imaginário, no espaço do neocolonialismo, não pode ser mais o da ignorância ou da 
ingenuidade, nutrido por uma manipulação simplista dos dados oferecidos pela experiência imediata do autor, mas se afirmaria mais e mais como uma escritura sobre outra escritura. A segunda obra, já que ela em geral comporta uma crítica da obra anterior, impõe-se com a violência desmistificadora das planchas anatômicas que deixam a nu a arquitetura do corpo humano. A propaganda torna-se eficaz porque o texto fala a linguagem de nosso tempo (SANTIAGO, 2000, p. 20-21).

Esse segundo texto pode ser irônico não apenas em relação ao cânone literário de países centrais, mas na periferia dialoga com sarcasmo sobre sua própria origem e de países vizinhos. $\mathrm{O}$ escritor Copi, em $\mathrm{O}$ Uruguai seguido de A Internacional Argentina, coloca a literatura latinoamericana num entre-lugar, desafiando as instâncias de poder. $O$ sarcasmo é visivel:

Para isso, seria necessário antes de qualquer coisa catequizar a África, tarefa tão utópica quanto iniciar um polonês na macumba. Perguntou-me muito polidamente se eu seria favorável, uma vez eleito, a um projeto de imigração maciça de negros para a Argentina. Fiquei entusiasmado com a ideia; sempre pensei que a Argentina sofria de um complexo de inferioridade em relação ao vizinho, o colosso brasileiro, pelo fato de não ter raízes negras. Nossa falta de pitoresca nacional vem daí, apesar de todos os nossos esforços para remediá-lo (COPI, 2015, p. 162).

Não se trata apenas de literatura de subversão, mas de antropofagia sobre si mesma e sobre as outras, parasitando e explodindo os conceitos de domínio e de poder: a religião, a ditadura militar, a maternidade e outros temas relacionados à América Latina, inseridos na literatura do escritor Copi, exilado na França. O escritor Schroeder, por sua vez, instaura a possibilidade do afeto em detrimento do que o próprio narrador afirma: "(...) pois não há dor maior que o da impossibilidade." (SCHROEDER, 2014,p. 75, grifos meus).

As fantasias eletivas representam a possibilidade do não lugar se tornar lugar; da ausência se tornar presença; do desafeto se tornar afeto; 
da impessoalidade se tornar amizade. Nas letras da última parte, justamente as fantasias eletivas, se a Copi se suicidou, Renê continua sentindo a perda desse relacionamento na memória, em meio à impessoalidade de uma recepção de hotel:

"Acabei me acostumando com a vida nos hotéis. O silêncio das quatro paredes, os olhares curiosos dos recepcionistas, a impessoalidade de tudo: você é apenas um número, o do seu quarto." Disse certa vez um hóspede para Renê, que fingiu um sorriso. (SCHROEDER, 2014, p. 109 - grifos meus).

Instaura-se uma literatura que se desvia da normalidade, a exemplo do escritor Copi, criando-se certo confronto entre a normalidade de Renê em relação à personagem Copi na forma de contrastes. A relação é desviante da norma mercantilista e mediada pelo dinheiro. Após o suicídio, Copi deixa poesias, fotografias, literatura e outros temas escritos, além da biblioteca, abrindo para Renê um novo mundo cultural:

A América Latina institui seu lugar no mapa da civilização ocidental graças ao movimento de desvio da norma, ativo e destruidor, que transfigura os elementos feitos e imutáveis que os europeus exportavam para o Novo Mundo. (SANTIAGO, 2000, p. 16).

A crítica Renata Pimentel Teixeira, em sua Tese de Doutorado, aponta para o mesmo sentido em relação à literatura do escritor Copi que, em certo sentido, pode ser aplicado ao romance de Schroeder:

O travestismo, o cruzamento de fronteiras tão forte em sua obra, estimula em matéria de identidade, o impensado e o arriscado, o inexplorado e o ambíguo, em vez do consensual e do assegurado, do conhecido e do assentado. Enfim, compreende uma experimentação que dificulta o retorno do eu e do nós ao idêntico, ao normatizado e, pretendidamente, "normalizado". (TEIXEIRA, 2007, p. 178).

$\mathrm{Na}$ última letra do abecedário, o que fica é a amizade e a necessidade de afeto: 


\begin{abstract}
"Ei, Ratón, você confia em mim?"
"Claro, claro, você é minha amiga, porra..."

Renê chacoalhou a cabeça, achando engraçada a pergunta, fechou a porta e foi embora. Copi sorriu, satisfeita, e fitou a porta por uns instantes, deixaria a porta de fora, perdoaria as entradas e saídas, pensou. E começou a acariciar as paredes. (SCHROEDER, 2014, P. 111).
\end{abstract}

\title{
REFERÊNCIAS
}

AUGÉ, Marc. Não Lugares: introdução a uma antropologia da supermodernidade. Campinas, SP: Papirus, 1994.

COPI. O uruguaio, seguido de A Internacional Argentina. Rio de Janeiro: Rocco, 2015.

DEBORD, Guy. A sociedade do espetáculo: comentários sobre a sociedade do espetáculo. Rio de Janeiro: Contraponto, 1997.

GOETHE, Johann Wolfgang Von. As afinidades eletivas. 1 ed. São Paulo: Penguin Classics Companhia das Letras, 2014.

SANTIAGO, Silviano. O entre-lugar do discurso latino americano. In: Uma literatura nos trópicos. 2 ed. Rio de Janeiro: Rocco, 2000.

SCHROEDER, Carlos Henrique. As fantasias eletivas. 1 ed. Rio de Janeiro: Record, 2014.

As certezas e as palavras. Jaraguá do Sul, SC: Editora da Casa, 2010.

. O ensaio do vazio. Rio de Janeiro: 7Letras, 2006.

- O ensaio do vazio: histórias em quadrinhos. Rio de Janeiro:

7Letras, 2012. 
TEIXEIRA, Renata Pimentel. COPI: transgressão e escrita transformista. 2007. Tese (Doutorado) - Universidade Federal de Pernambuco.

Recebido em: 26/08/2016

Aceito em: 13/09/2016 